\title{
Effect of flunixin meglumine and carprofen on pregnancy rates in dairy cattle
}

\author{
X. von Krueger and W. Heuwieser ${ }^{1}$ \\ Clinic for Animal Reproduction, Faculty of Veterinary Medicine, Freie Universitaet, 14163 Berlin, Germany
}

\begin{abstract}
Embryonic losses contribute considerably to low pregnancy rates. Between $\mathrm{d} 8$ and 17 after breeding, the conceptus secretes interferon- $\tau$ as a mechanism for maternal recognition of pregnancy and maintenance of the corpus luteum. Nonsteroidal antiinflammatory drugs inhibit the synthesis of prostaglandin $\mathrm{F}_{2 \alpha}$ by suppressing the enzyme cyclooxygenase. Flunixin meglumine (FM) has been demonstrated to delay luteolysis and to support embryonic survival. The objective of this study was to evaluate the effect of FM and carprofen on conception rates in dairy heifers and cows, respectively. In experiment 1, the effect of FM on pregnancy rates and progesterone concentrations in dairy heifers was tested. A total of 391 heifers were randomly assigned to 1 of 2 groups. Heifers in the treatment group $(\mathrm{n}=197)$ received $2.2 \mathrm{mg}$ of FM i.m. $/ \mathrm{kg}$ of body weight twice on d 14/15 and 15/16 after insemination, whereas heifers in the control group $(\mathrm{n}=194)$ remained untreated. Blood samples from 388 heifers were taken on d 14/15 and 21/22 after artificial insemination and analyzed for progesterone. Pregnancy rates were 58.2 and $54.8 \%$ for the control and treatment groups, respectively. Mean progesterone concentrations were not affected by treatment and number of artificial insemination service (first or second artificial insemination service), but were affected by time and time $\times$ pregnancy status. In experiment 2 , the objective was to verify the effects of carprofen, a longer acting nonsteroidal antiinflammatory drug and to evaluate its effect on conception rate to first service in dairy cows. A total of 380 cows were randomly assigned to 1 of 2 treatment groups. Cows in the treatment group $(\mathrm{n}=194)$ received $1.4 \mathrm{mg}$ of carprofen s.c./kg of body weight on d 15 after insemination, whereas cows in the control group $(\mathrm{n}=186)$ remained untreated. Pregnancy was diagnosed between d 40 and 47 after insemination. Conception rates to first service were 35.5 and $33.0 \%$ in the control and treatment groups, respectively. Neither flunixin meglumine nor carprofen improved conception rates to first
\end{abstract}

Received January 1, 2010.

Accepted August 1, 2010.

${ }^{1}$ Corresponding author: heuwieser.wolfgang@vetmed.fu-berlin.de service in dairy cattle in the dosage and administration schedule tested.

Key words: dairy cattle, nonsteroidal antiinflammatory drug, pregnancy rate, progesterone

\section{INTRODUCTION}

Numerous factors contribute to suboptimal reproductive performance in dairy cattle (Chebel et al., 2004; Demetrio et al., 2007; Santos et al., 2009). Although fertilization rates approach $100 \%$ in heifers (Santos et al., 2004) and around $77 \%$ in lactating dairy cows (Sartori et al., 2002), conception rates to first service established at the time of pregnancy diagnosis are considerably lower (Lucy, 2001; Santos et al., 2004; Demetrio et al., 2007). This difference is attributable to embryonic death occurring within the first few weeks after breeding. Pregnancy losses vary between $3.2 \%$ (Silke et al., 2002) and $42.7 \%$ (Cartmill et al., 2001) and have been associated with several factors, such as heat stress, milk yield, clinical mastitis, or progesterone concentrations (Mann and Lamming, 2001; Chebel et al., 2004; Green et al., 2005). Approximately $40 \%$ of embryonic losses occur between d 8 and 17 of pregnancy (Thatcher et al., 1994).

During early pregnancy, complex interactions between the embryo and the maternal environment occur. A trophoblastic protein, IFN- $\tau$, is produced by the embryo to prevent luteolysis induced by a pulsatile release of $\mathrm{PGF}_{2 \alpha}$ from the uterus (Bazer, 1992; Demmers et al., 2001) and supports the recognition of pregnancy by the dam. This process occurs between d 14 and 17 of pregnancy (Bazer et al., 1997). With corpus luteum maintenance, adequate progesterone secretion is maintained to establish pregnancy (Okuda et al., 2002). This is achieved by suppressing the oxytocin-dependent pulsatile release of $\mathrm{PGF}_{2 \alpha}$ from the endometrium through inhibition of oxytocin receptor expression (Farin et al., 1990; Bazer et al., 1997).

Pregnancy is associated with an increase in circulating progesterone concentration on d 4 or 5 after AI. One problem that may arise is asynchrony between mother and embryo (Green et al., 2005). Delayed increase or an insufficient secretion of progesterone during the early luteal phase may cause decelerated embryonic growth 
(Kerbler et al., 1997; Mann et al., 1999; Mann and Lamming, 2001). If the conceptus has not continued to develop at an appropriate rate, it will not able to produce sufficient IFN- $\tau$ to inhibit $\mathrm{PGF}_{2 \alpha}$ synthesis (Mann and Lamming, 2001). The subsequent luteolysis interrupts the required secretion of progesterone and results in embryonic loss during early pregnancy (Thatcher et al., 2001). Low progesterone during d 5 to 7 after AI has been associated with low fertility in dairy cows (Stronge et al., 2005). Lactating cows with milk progesterone concentrations exceeding $1.0 \mathrm{ng} / \mathrm{mL}$ within $5 \mathrm{~d}$ after $\mathrm{AI}$ and $\geq 2.0 \mathrm{ng} / \mathrm{mL}$ thereafter (i.e., until d 35 to 45 after AI) had a greater pregnancy rate $(87 \%)$ compared with the pregnancy rate $(33 \%)$ of cows with insufficient progesterone concentration or a delayed increase (Hommeida et al., 2004).

Nonsteroidal antiinflammatory drugs (NSAID) block the synthesis of prostaglandins, including $\mathrm{PGF}_{2 \alpha}$, via inhibition of the 2 isoforms of cyclooxygenase (COX, EC 1.14.99.1) COX-1 and COX-2 (Anderson et al., 1990). These enzymes are the essential catalysts at the beginning of prostaglandin synthesis. This inhibitory effect has been used to delay luteolysis for $1 \mathrm{~d}$ in dairy heifers after a 7-d treatment period with flunixin meglumine (FM) (Aiumlamai et al., 1990). A potential positive effect on pregnancy rates through the application of NSAID has been hypothesized, particularly at the critical time of pregnancy recognition, between d 14 and 17 after breeding (Guzeloglu et al., 2007; Erdem and Guzeloglu, 2010). This could provide more time for the embryo to secrete sufficient IFN- $\tau$ for maternal recognition of pregnancy. Current evidence regarding the use of NSAID to improve pregnancy rates in cattle is controversial.

Most research has been conducted with FM, which non-selectively inhibits COX. Several recent studies provide evidence of positive effects on subsequent reproductive performance from FM administered 14 to 17 $\mathrm{d}$ after breeding. Pregnancy rates were considerably higher in 2 studies conducted with beef heifers after treatment with FM $(1.1 \mathrm{mg} / \mathrm{kg}$ of BW) on d 14 after AI compared with untreated control groups (84 vs. $76 \%$, Merrill et al., 2003; 71 vs. 61\%, Merrill et al., 2007). Flunixin meglumine application at a dose of $1.1 \mathrm{mg} /$ $\mathrm{kg}$ of BW on d 15 and 16 after AI also increased pregnancy rate (76.9 vs. $50.0 \%$ ) in dairy heifers (Guzeloglu et al., 2007). Other research, however, has not shown FM to have any effect on pregnancy rates. Recently, it was demonstrated (Rabaglino et al., 2010) that FM administration on d 15 and 16 after AI did not have an effect on pregnancy rates (FM, 59.5\%; CON, 59.4\%). In addition, an earlier treatment on d 13 after AI did not improve pregnancy rate in beef heifers (56 vs. $55 \%$ ) and beef cows (45 vs. $42 \%$; Geary et al., 2005). In one experiment within that study (Geary et al., 2005), beef heifers were divided into control and treatment groups, and heifers were driven through an animal-handling facility for FM administration. Pregnancy rates were lower $(P<0.025)$ in the treatment group $(65 \%)$ compared with the control group (71\%). The authors assumed a negative effect from handling stress (Geary et al., 2005).

The effect of FM on plasma progesterone (P4) concentrations was examined by Merrill et al. (2007) in a $2 \times 2$ factorial design applying stress through transportation and FM as treatments. The P4 concentrations were higher for cattle that had been transported and treated with FM $(3.3 \pm 0.2 \mathrm{ng} / \mathrm{mL})$ compared with untreated controls $(2.9 \pm 0.2 \mathrm{ng} / \mathrm{mL})$. Animals that were transported but not treated had also elevated P4 concentrations (3.4 $\pm 0.2 \mathrm{ng} / \mathrm{mL}$; Merrill et al., 2007).

Carprofen is also a nonselective NSAID. It has a longer lasting effect compared with FM. The elimination half-life of carprofen (44.5 to 64.6 h; Ludwig et al., 1989 ) is even longer than that of meloxicam. Carprofen has a species-dependent selectivity to the COX isoforms COX-1 and COX-2. In dogs, several studies have demonstrated selectivity of carprofen for COX-2 (Ricketts et al., 1998; Brideau et al., 2001), whereas others have not (McKellar et al., 1994; Brideau et al., 2001). Studies in horses have indicated a nonselective effect of carprofen at a dose of $0.7 \mathrm{mg} / \mathrm{kg}$ of BW (Brideau et al., 2001; Lees et al., 2004), whereas at higher doses $(4.0 \mathrm{mg} / \mathrm{kg}$ of BW), a considerable inhibition of COX-2 has been shown (Lees et al., 2004). Characteristically for ruminants, carprofen showed an antiinflammatory effect without selectivity in sheep (Cheng et al., 2002). Commercially available products contain a racemic mixture of 2 enantiomeric isoforms of carprofen. Research in vitro has demonstrated that the $S(+)$-enantiomer is more selective for COX-2 than the $R(-)$-enantiomer of carprofen (Ricketts et al., 1998). To our knowledge, no information is available on the effect of carprofen on dairy cattle reproductive performance.

One potential use of NSAID is to target pregnancy losses in cattle. However, science-based evidence is limited and controversial regarding the prophylactic use of NSAID to increase reproductive performance by supporting embryonic survival. Thus, the first objective of this study was to evaluate the effect of administering FM twice on pregnancy rate in dairy heifers. Our aim was to (1) compare the effect of FM on pregnancy rate administered twice on d 14 and 15 or d 15 and 16 , respectively, and (2) measure serum concentrations of progesterone in dairy heifers treated with FM. We also aimed to determine if a single administration of carprofen could increase conception rates to first service in lactating dairy cows. Carprofen was chosen because of 
its longer lasting effect compared with FM, allowing a single administration and a 0 -d withdrawal period for milk in Germany.

\section{MATERIALS AND METHODS}

\section{Animals and Treatments}

All procedures in this trial were conducted according to the International Cooperation on Harmonization of Technical Requirements for Registration of Veterinary Medicinal Products regulations relating to good clinical practice and clinical trials. Experiment 1 was conducted on a commercial heifer rearing facility in Germany. A total of 2,150 Holstein cattle from $7 \mathrm{~d}$ to 18 mo of age were housed in different freestall barns. Study animals $(\mathrm{n}=413)$ were grouped in pens of 9 animals and fed a TMR based on corn silage (60\%) and grass silage (40\%). At the age of 13 mo, heifers were weighed twice a week and considered to be eligible to be bred if their BW exceeded $400 \mathrm{~kg}$. Groups of 9 heifers were formed and assigned to breeding pens 9 to $10 \mathrm{~d}$ before AI. For estrus synchronization, heifers received $0.15 \mathrm{mg}$ of cloprostenol i.m./kg BW (Gonadovet, AniMedica GmbH, Senden-Bösensell, Germany) on Mondays. Estrus was observed twice daily for $30 \mathrm{~min}$, Wednesdays to Fridays. All heifers in estrus were artificially inseminated by 1 of 2 AI technicians with semen from 6 different sires (A, 34.9\%; B, 33.7\%; C, 18.6\%; D, 5.8\%; E, 3.8\%; F, $3.2 \%)$

A total of 413 Holstein-Friesian heifers were enrolled in the study and assigned to 1 of 2 treatment groups using a random treatment allocation plan generated before the initiation of the trial with a random number generator (Excel 2003, Microsoft Corp., Redmond, WA). Between June and November 2007, 22 replicates with an average of $19( \pm 13)$ heifers were conducted. Of the 413 heifers enrolled in the study, 22 were excluded (more than $2 \mathrm{AI}, \mathrm{n}=9$; illness, $\mathrm{n}=3$; extreme defensive behavior, $\mathrm{n}=10$ ). Data from 391 heifers were included in the statistical analyses. For analysis of conception rate to first service, heifers with only first AI $(\mathrm{n}=307)$ were included.

Heifers in the treatment group $\left(\mathbf{T X}_{\mathbf{F M}}, \mathrm{n}=197\right)$ received $2.2 \mathrm{mg}$ of FM i.m./kg of BW (Finadyne, Intervet Deutschland GmbH, Unterschleißheim, Germany) twice, $24( \pm 1) \mathrm{h}$ apart on d 14 and $15(\mathrm{n}=82)$ or $\mathrm{d} 15$ and $16(\mathrm{n}=115)$ after AI, respectively, as is approved in Germany. Animals in the control group $\left(\mathbf{C O N}_{\mathbf{F M}}, \mathrm{n}=\right.$ 194) remained untreated. Inclusion criterion for enrollment was first AI service $(\mathrm{n}=307)$ or second AI service $(\mathrm{n}=84)$, performed on Wednesdays or Thursdays. If heifers showed estrus again between first AI service and day of treatment, another AI was performed. These heifers were not treated and were reenrolled in the study as heifers with second AI service. They were then reassigned randomly to control or treatment group. If heifers showed estrus again between first AI service and pregnancy diagnosis, but after treatment, a negative pregnancy diagnosis was assumed. These heifers were not reenrolled in the study. Pregnancy was diagnosed on d 39 or 41 after AI by transrectal palpation.

Blood samples from 388 heifers $\left(\mathrm{CON}_{\mathrm{FM}}, \mathrm{n}=192\right.$; $\left.\mathrm{TX}_{\mathrm{FM}}, \mathrm{n}=196\right)$ were collected before treatment on $\mathrm{d}$ 14 or 15 after $\mathrm{AI}$ and $7 \mathrm{~d}$ after treatment on d 21 or 22 after AI by coccygeal venipuncture for P4 concentration measurements. Blood samples were centrifuged at $3,500 \times g$ for $15 \mathrm{~min}$. Serum was divided into 2 aliquots, transferred into serum tubes, and stored at $-20^{\circ} \mathrm{C}$ until analysis. Serum concentrations of $\mathrm{P} 4$ were analyzed by a competitive solid-phase chemiluminescent immunoassay (Immulite 2000, Siemens Healthcare Diagnostics GmbH, Eschborn, Germany) in a commercial laboratory. Interassay and intraassay coefficients of variation were 9.6 and $14.2 \%$, respectively.

In both groups, heifers were managed in the same barn with head locks for collecting blood samples and injections of FM. Consequently, all handling was identical for both groups. Control heifers were not injected with a placebo. It is reasonable to assume that the injection process itself did not have an effect on pregnancy outcome.

Experiment 2 was conducted on a commercial dairy farm in Germany. A total of 1,200 dairy cows were housed in freestall barns. Average milk yield during the study period was $9,600 \mathrm{~kg} / \mathrm{yr}$, with $4.3 \%$ fat and $3.43 \%$ protein. Energy-corrected milk yield (based on $4.0 \%$ fat and $3.4 \%$ protein) was $9,964 \mathrm{~kg} / \mathrm{yr}$.

A total of 380 Holstein Friesian cows (127 primiparous and 253 multiparous cows) were enrolled in the study and assigned to 1 of 2 treatment groups using a random treatment allocation plan generated before the initiation of the trial using a random number generator.

The cows had been synchronized using an Ovsynch protocol consisting of an injection of GnRH $(100 \mu \mathrm{g}$ of gonadorelin, Ovarelin; CEVA Tiergesundheit $\mathrm{GmbH}$, Düsseldorf, Germany) followed $7 \mathrm{~d}$ later with an injection of $\mathrm{PGF}_{2 \alpha}$ (0.5 mg of cloprostenol, Estrumate, Intervet Tiergesundheit $\mathrm{GmbH}$, Unterschleißheim, Germany), and a second injection of GnRH $56 \mathrm{~h}$ after the last dose of $\mathrm{PGF}_{2 \alpha}$. Timed AI was performed $16 \mathrm{~h}$ after the second injection of GnRH by one AI technician. Data on second services and AI sires were not accessible.

Cows from the treatment group $\left(\mathbf{T X}_{\mathbf{C}}, \mathrm{n}=194\right)$ received $1.4 \mathrm{mg}$ of carprofen s.c./kg of BW (Rimadyl, Pfizer Tiergesundheit GmbH, Berlin, Germany) on d 
Table 1. Serum progesterone concentrations (mean \pm SE) of pregnant and nonpregnant heifers on d 14/15 and d 21/22 after AI

\begin{tabular}{|c|c|c|}
\hline \multirow[b]{2}{*}{$\begin{array}{l}\text { Day of } \\
\text { sampling }\end{array}$} & \multicolumn{2}{|c|}{ Progesterone concentration, $\mathrm{ng} / \mathrm{mL}$} \\
\hline & $\begin{array}{l}\text { Pregnant heifers } \\
\quad(\mathrm{n}=221)\end{array}$ & $\begin{array}{l}\text { Nonpregnant heifers } \\
\quad(\mathrm{n}=167)\end{array}$ \\
\hline $\begin{array}{l}14 / 15 \\
21 / 22\end{array}$ & $\begin{array}{l}8.27 \pm 0.21^{\mathrm{a}, \mathrm{c}} \\
9.36 \pm 0.25^{\mathrm{b}, \mathrm{d}}\end{array}$ & $\begin{array}{l}7.06 \pm 0.28^{\mathrm{b}, \mathrm{c}} \\
2.26 \pm 0.26^{\mathrm{b}, \mathrm{d}}\end{array}$ \\
\hline
\end{tabular}

15 after AI. Animals of the control group $\left(\mathbf{C O N}_{\mathbf{C}}, \mathrm{n}\right.$ $=186$ ) remained untreated. Pregnancy was diagnosed between d 40 and 47 after AI by transrectal palpation.

Cows from both groups were managed in the same barn with head locks for injection of carprofen. Consequently, all handling was the same for both groups. Control cows were not injected with a placebo.

\section{Statistical Analyses}

Data were analyzed using SPSS for Windows (PASW Statistics 18.0, SPSS Inc., Munich, Germany). Effect of treatment on pregnancy outcome was evaluated using chi-squared analyses.

In experiment 1, a logistic regression model for a positive pregnancy diagnosis included time of handling study animals (d 14/15 or d 15/16 after AI), AI technicians, AI sires, number of service, and serum P4 concentrations on d 14/15 and d 21/22 as covariates. Adjusted odds ratios (OR), confidence intervals $\left(\mathbf{C I}_{\mathbf{9 5}}\right)$, and $P$-values are reported. Serum P4 concentrations on d 14/15 and d 15/16 were compared in a generalized linear model for repeated measurements with treatment $(0=\mathrm{CON}, 1=\mathrm{TX})$, number of AI service $(0=$ first $\mathrm{AI}$ service, $1=$ second AI service), and pregnancy status $(0=$ non-pregnant, $1=$ pregnant $)$ as fixed factors. Differences in $\mathrm{P} 4$ between pregnancy status and number of AI service were evaluated using one-way ANOVA.

Table 2. Conception rates to first service in experiment 2 control and treatment groups

\begin{tabular}{lll}
\hline Conception rate & $\begin{array}{c}\text { Control group } \\
(\mathrm{n}=186)\end{array}$ & $\begin{array}{c}\text { Treatment group } \\
(\mathrm{n}=194)\end{array}$ \\
\hline All cows, \% & $35.5^{\mathrm{a}}(66 / 186)$ & $33.0^{\mathrm{ab}}(64 / 194)$ \\
Primiparous cows, \% & $43.5^{\mathrm{a}}(27 / 62)$ & $46.2^{\mathrm{a}}(30 / 65)$ \\
Multiparous cows, \% & $31.5^{\mathrm{a}}(39 / 124)$ & $26.4^{\mathrm{b}}(34 / 129)$ \\
\hline
\end{tabular}

a,b Numbers within a column with different superscripts differ $(P<$ $0.05)$.

${ }^{1} \mathrm{TX}=$ treatment group treated with $1.4 \mathrm{mg} / \mathrm{kg}$ of BW of carprofen (Rimadyl, Pfizer Tiergesundheit GmbH, Berlin, Germany) on d 15 after AI.
Differences in P4 between d 14/15 and d 21/22 were evaluated using paired-sample $t$-test.

In experiment 2, a logistic regression model for a positive pregnancy diagnosis included parity $(0=$ primiparous, 1 = multiparous) as a covariate. Adjusted OR, $\mathrm{CI}_{95}$, and $P$-values are reported. Level of significance for all statistical analyses was $\alpha=0.05$. For logistic regression, confidence interval was set at $95 \%$.

\section{RESULTS}

\section{Experiment 1}

Because time of handling did not have an effect $(\mathrm{OR}=$ $\left.0.97, \mathrm{CI}_{95}=0.51-1.83, P=0.92\right)$ on the pregnancy outcome, the 2 treatment times were combined for further analysis. Similarly, sires $\left(\mathrm{OR}=1.1, \mathrm{CI}_{95}=0.94-1.3, P\right.$ $=0.25)$ and $\mathrm{AI}$ technicians $\left(\mathrm{OR}=1.0, \mathrm{CI}_{95}=1.0-1.0\right.$, $P=0.13)$ did not affect pregnancy outcome.

Pregnancy rates for heifers with only one AI ( $\mathrm{n}=$ 307 ) were $58.7 \%$ (88 of 150 ) and $58.6 \%$ (92 of 157 ) for the control and treatment groups, respectively $(P=$ 0.99). By including heifers with a second AI $(\mathrm{n}=391)$, pregnancy rates were $58.2 \%$ (113 of 194) and $54.8 \%$ (108 of 197) for the control and treatment groups, respectively $(P=0.50)$.

Serum progesterone concentrations (mean \pm SE) of pregnant and nonpregnant heifers on $\mathrm{d} 14 / 15$ and $\mathrm{d}$ 21/22 after AI are presented in Table 1 . Mean P4 concentrations were not affected by treatment $(P=0.90)$ or number of $\mathrm{AI}(P=0.09)$, but were affected by time $(P=0.008)$ and time $\times$ pregnancy status $(P<0.001)$.

\section{Experiment 2}

Conception rates to first service are presented in Table 2. Conception rates to first service were $35.5 \%$ (66 of 186) and $33.0 \%$ (64 of 194) for control and treatment groups, respectively $(P=0.61)$. Carprofen treatment did not have an effect on conception rates to first service in primiparous and multiparous cows $(P=0.77$ and $P$ $=0.37$, respectively). In all cows, the conception rate to first service for primiparous cows was significantly higher $(P=0.002)$ than that for multiparous cows (OR $\left.=2.01 ; \mathrm{CI}_{95}=1.29-3.13\right)$.

\section{DISCUSSION}

\section{Experiment 1: Flunixin Meglumine in Heifers}

It has been found that administration of FM (1.1 $\mathrm{mg} / \mathrm{kg}$ of BW) on d 15 and 16 reduced embryonic losses in heifers considerably (Guzeloglu et al., 2007). Significantly more heifers in the treatment group (76.9\%) became pregnant compared with heifers of a control 
group (50.0\%). The authors assumed that FM delayed luteolysis. Consequently, the embryos had more time to produce sufficient IFN- $\tau$ to prevent the regression of the corpus luteum (Guzeloglu et al., 2007). However, the evidence behind this study is limited because of the small sample size per group $(\mathrm{n}=26)$. In our study, 194 heifers received FM $(2.2 \mathrm{mg} / \mathrm{kg}$ of BW) on d 14/15 and 15/16 after AI, respectively, and 197 animals served as untreated controls. Pregnancy rates were $58.2 \%$ (113 of 194) and 54.8\% (108 of 197) for the control and treatment groups, respectively $(P=0.50)$.

These results clearly demonstrate that 2 injections of FM on d 14/15 and 15/16 after AI, respectively, did not have an effect on pregnancy rate $\left(\mathrm{CON}_{\mathrm{FM}}=\right.$ $58.2 \% ; \mathrm{TX}_{\mathrm{FM}}=54.8 \%$ ). These results are consistent with a recent study (Rabaglino et al., 2010) that tested a total of 323 heifers (158 treated, 165 untreated). The administration of FM (400 mg i.m.) on d 15 and 16 did not have an effect on pregnancy rates $(\mathrm{CON}=59.4 \%$; TX $=59.5 \%$ ). A previous study (Geary et al., 2005) demonstrated similar results. Even though distinct differences existed in the experimental design, such as treatment (single dose of $1.1 \mathrm{mg}$ of $\mathrm{FM} / \mathrm{kg}$ of BW), time of treatment (approximately d 13 after AI), and breed (beef heifers), pregnancy rates were similar to those of our experiment and did not differ between the control $(55 \%)$ and treatment $(56 \%)$ group. A second experiment in that study (Geary et al., 2005) found that pregnancy rates were reduced in heifers that had been exposed to stress while receiving FM (65\%) compared with control heifers that remained untreated (71\%). The authors assumed that intensive stress from handling (i.e., processing through a chute), occurring around the time of maternal recognition of pregnancy, may have decreased pregnancy rates and offset a positive effect from FM (Geary et al., 2005). Treatments were administered on d 14/15 and on d 15/16 after AI, respectively, to confirm previous results (Guzeloglu et al., 2007). It is possible that a later administration of FM (e.g., on d 17/18) could have changed pregnancy outcomes. Endometrial tissue from cyclic and pregnant cattle began to differ in secretion of $\mathrm{PGF}_{2 \alpha}$ on $\mathrm{d} 17$ after estrus (Thatcher et al., 1992).

In our trial, we used dairy heifers well adapted to human interaction and head locks. Therefore, stress through handling (i.e., restraining in head locks) was limited and identical for the treatment and control heifers in each pen except for the injection of FM. Although the intensity and duration of the stress through injection in our study was minimal compared with the processing of beef heifers through a chute, a negative effect for the treatment group cannot be completely excluded. However, it is reasonable to assume that the injection process itself did not have an effect on the pregnancy outcome. An overriding negative influence (i.e., stress through i.m. injection) on a positive effect on pregnancy recognition through FM is highly unlikely.

Others, however, have noted that FM appeared to decrease stress-induced embryonic losses in cows. Increased pregnancy rates after administration of FM between d 12 and 16 after AI (Merrill et al., 2007) or at the time of embryo transfer (Schrick et al., 1993; Purcell et al., 2005) have been reported previously.

It has been demonstrated that the suppressive effect of $\mathrm{FM}$ on $\mathrm{PGF}_{2 \alpha}$ synthesis reached its maximum $4 \mathrm{~h}$ after application and persisted for up to $8 \mathrm{~h}$ (Thun et al., 1993). To ensure the inhibition of prostaglandin synthesis for a longer period, it has been suggested that FM be administered every 4 to $6 \mathrm{~h}$ (Thun et al., 1993). Therefore, it is possible that the 24-h interval between the 2 treatments in our study was too long, potentially allowing the synthesis of $\mathrm{PGF}_{2 \alpha}$ to increase again after the first injection of FM and consequently triggering regression of the corpus luteum.

Mean $\mathrm{P} 4$ concentrations were not affected by treatment $(P=0.90)$ or number of AI $(P=0.09)$, but were affected by time $(P=0.008)$ and time $\times$ pregnancy status $(P<0.001)$. Significant differences in P4 concentrations between pregnant and nonpregnant females have been described to occur at the time of the expected onset of luteolysis on d 16 (Mann et al., 1999). Serum progesterone concentrations below $1.0 \mathrm{ng} / \mathrm{mL}$ on d 14/15 were identified in $12.5 \%$ of the control and in $14.7 \%$ of the treated heifers, indicating the absence of a functional corpus luteum. On the one hand, a low maternal progesterone environment predisposes an embryo to a slow rate of development (Mann et al., 1999; Mann and Lamming, 2001). Therefore, it is likely that these embryos were not able to produce sufficient concentrations of IFN- $\tau$ to prevent luteolysis resulting in abortion. On the other hand, the estrus observation protocol implemented on the farm (twice daily for 30 min) could have been insufficient to ensure accurate detection of all heifers in heat.

\section{Experiment 2: Carprofen in Lactating Dairy Cows}

Carprofen was chosen because its longer elimination half-life (44.5 to $64.6 \mathrm{~h}$; Ludwig et al., 1989) compared with FM or meloxicam allowed us to avoid repeated injections (e.g., every 4 to $6 \mathrm{~h}$ ), as has been recommended for FM (Thun et al., 1993). In addition, carprofen is approved in Germany for lactating dairy cows without a withdrawal period on milk, in contrast with meloxicam (5 d) and FM (1 d). To our knowledge, no information is available on the effect of carprofen on reproductive performance in dairy cattle. Thus, the objective of this 
study was to determine if a single administration of carprofen could increase conception rates to first service in lactating dairy cows.

The conception rate to first service could not be improved in the treatment group $(33.0 \%)$ compared with the control group (35.5\%). Our results are consistent with recent research employing short-acting FM in beef cattle (Geary et al., 2005) and dairy heifers (Rabaglino et al., 2010), and long-acting meloxicam in dairy heifers (Erdem and Guzeloglu, 2010) and repeat-breeder cows (Amiridis et al., 2009). All of these studies failed to show a positive effect on pregnancy rates. One study even described a significant negative effect of meloxicam on pregnancy rates (Erdem and Guzeloglu, 2010). Evidence of the latter study, however, is weak because pregnancy rates calculated were based on small animal numbers (treatment group: 9 pregnant heifers out of 37; untreated control group: 25 pregnant heifers out of 48).

In both experiments, pregnancy was diagnosed by transrectal palpation on d 39 or 41 after AI in heifers and on d 40 to 47 after AI in cows. Because of the subjective nature of the technique, some margin of error exists. As recently shown, however, early pregnancy diagnosis by rectal palpation between d 34 and 41 using the fetal membrane slip technique did not affect embryo viability (Romano et al., 2007). Unfortunately, a direct comparison of accuracies for the 2 techniques has not yet been accomplished.

Flunixin meglumine and carprofen have been approved for the treatment of pyrexia, acute bronchopneumonia, acute mastitis, endotoxemia, and lameness in dairy heifers and cows in Europe. In the United States, only FM has been approved for use in cattle. Our data and other findings (e.g., Rabaglino et al., 2010) provide strong evidence that NSAID administered within 2 to 3 wk after breeding for the treatment of inflammatory diseases do not compromise reproductive performance.

\section{CONCLUSIONS}

Data from both experiments provide strong evidence that NSAID administered after AI do not improve conception rates. This was true for 2 applications of FM $(2.2 \mathrm{mg} / \mathrm{kg}$ of BW) on d 14/15 and 15/16 in dairy heifers and for 1 application of carprofen $(1.4 \mathrm{mg}$ s.c./ $\mathrm{kg}$ of BW ) in lactating dairy cows. Therefore, we discourage attempts to improve reproductive performance in dairy cattle by use of FM or carprofen in the dosage and administration schedule tested.

\section{REFERENCES}

Aiumlamai, S., K. Odensvik, G. Stabenfeldt, and H. Kindahl. 1990. Regulation of prostaglandin biosynthesis with flunixin meglumine in the bovine species. Zentralbl. Veterinarmed. A 37:16-22.
Amiridis, G. S., T. Tsiligianni, E. Dovolou, C. Rekkas, D. Vouzaras, and I. Menegatos. 2009. Combined administration of gonadotropin-releasing hormone, progesterone, and meloxicam is an effective treatment for the repeat-breeder cow. Theriogenology 72:542548.

Anderson, K. L., C. A. Neff-Davis, L. E. Davis, and V. D. Bass. 1990. Pharmacokinetics of flunixin meglumine in lactating cattle after single and multiple intramuscular and intravenous administrations. Am. J. Vet. Res. 51:1464-1467.

Bazer, F. W. 1992. Mediators of maternal recognition of pregnancy in mammals. Proc. Soc. Exp. Biol. Med. 199:373-384.

Bazer, F. W., T. E. Spencer, and T. L. Ott. 1997. Interferon tau: A novel pregnancy recognition signal. Am. J. Reprod. Immunol. $37: 412-420$.

Brideau, C., C. Van Staden, and C. C. Chan. 2001. In vitro effects of cyclooxygenase inhibitors in whole blood of horses, dogs, and cats. Am. J. Vet. Res. 62:1755-1760.

Cartmill, J. A., S. Z. El-Zarkouny, B. A. Hensley, T. G. Rozell, J. F. Smith, and J. S. Stevenson. 2001. An alternative AI breeding protocol for dairy cows exposed to elevated ambient temperatures before or after calving or both. J. Dairy Sci. 84:799-806.

Chebel, R. C., J. E. Santos, J. P. Reynolds, R. L. Cerri, S. O. Juchem, and M. Overton. 2004. Factors affecting conception rate after artificial insemination and pregnancy loss in lactating dairy cows. Anim. Reprod. Sci. 84:239-255.

Cheng, Z., A. Nolan, and Q. A. McKellar. 2002. Anti-inflammatory effects of carprofen, carprofen enantiomers, and $\mathrm{N}^{\mathrm{G}}$-nitro-L-arginine methyl ester in sheep. Am. J. Vet. Res. 63:782-788.

Demetrio, D. G., R. M. Santos, C. G. Demetrio, and J. L. Vasconcelos. 2007. Factors affecting conception rates following artificial insemination or embryo transfer in lactating Holstein cows. J. Dairy Sci. 90:5073-5082.

Demmers, K. J., K. Derecka, and A. Flint. 2001. Trophoblast interferon and pregnancy. Reproduction 121:41-49.

Erdem, H., and A. Guzeloglu. 2010. Effect of meloxicam treatment during early pregnancy in Holstein heifers. Reprod. Domest. Anim. 45:625-628.

Farin, C. E., K. Imakawa, T. R. Hansen, J. J. McDonnell, C. N. Murphy, P. W. Farin, and R. M. Roberts. 1990. Expression of trophoblastic interferon genes in sheep and cattle. Biol. Reprod. $43: 210-218$

Geary, T. W., R. P. Ansotegui, M. D. MacNeil, A. J. Roberts, R. C. Waterman, M. D. MacNeil, E. E. Grings, B. D. Thompson, and R. J. Lipsey. 2005. Effects of flunixin meglumine on pregnancy establishment in beef cattle. J. Anim. Sci. 88:943-949.

Green, M. P., M. G. Hunter, and G. E. Mann. 2005. Relationships between maternal hormone secretion and embryo development on day 5 of pregnancy in dairy cows. Anim. Reprod. Sci. 88:179-189.

Guzeloglu, A., H. Erdem, M. K. Saribay, W. W. Thatcher, and T. Tekeli. 2007. Effect of the administration of flunixin meglumine on pregnancy rates in Holstein heifers. Vet. Rec. 160:404-406.

Hommeida, A., T. Nakao, and H. Kubota. 2004. Luteal function and conception in lactating cows and some factors influencing luteal function after first insemination. Theriogenology 62:217-225.

Kerbler, T. L., M. M. Buhr, L. T. Jordan, K. E. Leslie, and J. S. Walton. 1997. Relationship between maternal plasma progesterone concentration and interferon-tau synthesis by the conceptus in cattle. Theriogenology 47:703-714.

Lees, P., J. Giraudel, M. F. Landoni, and P. L. Toutain. 2004. PK-PD integration and PK-PD modelling of nonsteroidal anti-inflammatory drugs: Principles and applications in veterinary pharmacology. J. Vet. Pharmacol. Ther. 27:491-502.

Lucy, M. C. 2001. Reproductive loss in high-producing dairy cattle: Where will it end? J. Dairy Sci. 84:1277-1293.

Ludwig, B., J. C. Jordan, W. F. Rehm, and R. Thun. 1989. Carprofen in veterinary medicine. I. Plasma disposition, milk excretion and tolerance in milk-producing cows. Schweiz. Arch. Tierheilkd. 131:99-106.

Mann, G. E., and G. E. Lamming. 2001. Relationship between maternal endocrine environment, early embryo development and 
inhibition of the luteolytic mechanism in cows. Reproduction 121:175-180.

Mann, G. E., G. E. Lamming, R. S. Robinson, and D. C. Wathes. 1999. The regulation of interferon-tau production and uterine hormone receptors during early pregnancy. J. Reprod. Fertil. Suppl. 54:317-328.

McKellar, Q. A., P. Delatour, and P. Lees. 1994. Stereospecific pharmacodynamics and pharmacokinetics of carprofen in the dog. J. Vet. Pharmacol. Ther. 17:447-454.

Merrill, M. L., R. P. Ansotegui, P. D. Burns, M. D. MacNeil, and T. W. Geary. 2007. Effects of flunixin meglumine and transportation on establishment of pregnancy in beef cows. J. Anim. Sci. 85:1547-1554.

Merrill, M. L., R. P. Ansotegui, N. E. Wamsley, P. D. Burns, and T. W. Geary. 2003. Effects of flunixin meglumine on embryonic loss in stressed beef cows. Proc. West. Sec. Am. Soc. Anim. Sci. $54: 53-56$.

Okuda, K., Y. Miyamoto, and D. J. Skarzynski. 2002. Regulation of endometrial prostaglandin $\mathrm{F}$ (2alpha) synthesis during luteolysis and early pregnancy in cattle. Domest. Anim. Endocrinol. $23: 255-264$.

Purcell, S. H., W. E. Beal, and K. R. Gray. 2005. Effect of a CIDR insert and flunixin meglumine, administered at the time of embryo transfer, on pregnancy rate and resynchronization of estrus in beef cattle. Theriogenology 64:867-878.

Rabaglino, M. B., C. A. Risco, M. J. Thatcher, F. Lima, J. E. P. Santos, and W. W. Thatcher. 2010. Use of a five-day progesteronebased timed AI protocol to determine if flunixin meglumine improves pregnancy per timed AI in dairy heifers. Theriogenology 73:1311-1318.

Ricketts, A. P., K. M. Lundy, and S. B. Seibel. 1998. Evaluation of selective inhibition of canine cyclooxygenase 1 and 2 by carprofen and other nonsteroidal anti-inflammatory drugs. Am. J. Vet. Res. $59: 1441-1446$.

Romano, J. E., J. A. Thompson, D. C. Kraemer, M. E. Westhusin, D. W. Forrest, and M. A. Tomaszweski. 2007. Early pregnancy diagnosis by palpation per rectum: influence on embryo/fetal viability in dairy cattle. Theriogenology 67:486-493.
Santos, J. E., H. M. Rutigliano, and M. F. Sa Filho. 2009. Risk factors for resumption of postpartum estrous cycles and embryonic survival in lactating dairy cows. Anim. Reprod. Sci. 110:207-221.

Santos, J. E., W. W. Thatcher, R. C. Chebel, R. L. Cerri, and K. N. Galvao. 2004. The effect of embryonic death rates in cattle on the efficacy of estrus synchronization programs. Anim. Reprod. Sci. 82-83:513-535.

Sartori, R., R. Sartor-Bergfelt, S. A. Mertens, J. N. Guenther, J. J. Parrish, and M. C. Wiltbank. 2002. Fertilization and early embryonic development in heifers and lactating cows in summer and lactating and dry cows in winter. J. Dairy Sci. 85:2803-2812.

Schrick, F. N., E. K. Inskeep, and R. L. Butcher. 1993. Pregnancy rates for embryos transferred from early postpartum beef cows into recipients with normal estrous cycles. Biol. Reprod. 49:617-621.

Silke, V., M. G. Diskin, D. A. Kenny, M. P. Boland, P. Dillon, J. F. Mee, and J. M. Sreenan. 2002. Extent, pattern and factors associated with late embryonic loss in dairy cows. Anim. Reprod. Sci. $71: 1-12$.

Stronge, A. J., J. M. Sreenan, M. G. Diskin, J. F. Mee, D. A. Kenny, and D. G. Morris. 2005. Post-insemination milk progesterone concentration and embryo survival in dairy cows. Theriogenology 64:1212-1224.

Thatcher, W. W., G. Danet-Desnoyers, and C. Wetzels. 1992. Regulation of bovine endometrial prostaglandin secretion and the role of bovine trophoblast protein-1 complex. Reprod. Fertil. Dev. 4:329-334.

Thatcher, W. W., A. Guzeloglu, R. Mattos, M. Binelli, T. R. Hansen, and J. K. Pru. 2001. Uterine-conceptus interactions and reproductive failure in cattle. Theriogenology 56:1435-1450.

Thatcher, W. W., C. R. Staples, G. Danet-Desnoyers, B. Oldick, and E. P. Schmitt. 1994. Embryo health and mortality in sheep and cattle. J. Anim. Sci. 72:16-30.

Thun, R., H. Kundig, K. Zerobin, H. Kindahl, B. K. Gustafsson, and W. Ziegler. 1993. (Uterine motility of cattle during late pregnancy, labor and puerperium. III. Use of flunixin meglumine and endocrine changes). Schweiz. Arch. Tierheilkd. 135:333-344. 